\title{
A pilot goal-directed perfusion initiative is associated with less acute kidney injury after cardiac surgery
}

\author{
J. Trent Magruder, MD, ${ }^{\mathrm{a}}$ Todd C. Crawford, MD, ${ }^{\mathrm{a}}$ Herbert Lynn Harness, CCP, LP, ${ }^{\mathrm{a}}$ Joshua C. Grimm, MD, ${ }^{\mathrm{a}}$ \\ Alejandro Suarez-Pierre, MD, ${ }^{a}$ Chad Wierschke, CCP, LP, ${ }^{\mathrm{a}}$ Jim Biewer, CCP, LP, ${ }^{\mathrm{a}}$ Charles Hogue, MD, \\ Glenn R. Whitman, MD, ${ }^{a}$ Ashish S. Shah, MD, ${ }^{c}$ and Viachaslau Barodka, MD $^{b}$
}

\begin{abstract}
Background: We sought to determine whether a pilot goal-directed perfusion initiative could reduce the incidence of acute kidney injury after cardiac surgery.

Methods: On the basis of the available literature, we identified goals to achieve during cardiopulmonary bypass (including maintenance of oxygen delivery $>300 \mathrm{~mL} \mathrm{O} 2 / \mathrm{min} / \mathrm{m}^{2}$ and reduction in vasopressor use) that were combined into a goal-directed perfusion initiative and implemented as a quality improvement measure in patients undergoing cardiac surgery at Johns Hopkins during 2015. Goal-directed perfusion initiative patients were matched to controls who underwent cardiac surgery between 2010 and 2015 using propensity scoring across 15 variables. The primary and secondary outcomes were the incidence of acute kidney injury and the mean increase in serum creatinine within the first 72 hours after cardiac surgery.
\end{abstract}

Results: We used the goal-directed perfusion initiative in 88 patients and matched these to 88 control patients who were similar across all variables, including mean age (61 years in controls vs 64 years in goal-directed perfusion initiative patients, $P=.12)$ and preoperative glomerular filtration rate $(90 \mathrm{vs} 83 \mathrm{~mL} / \mathrm{min}, P=.34)$. Controls received more phenylephrine on cardiopulmonary bypass (mean 2.1 vs $1.4 \mathrm{mg}, P<.001$ ) and had lower nadir oxygen delivery (mean 241 vs $301 \mathrm{~mL} \mathrm{O} 2 / \mathrm{min} / \mathrm{m}^{2}, P<.001$ ). Acute kidney injury incidence was $23.9 \%$ in controls and $9.1 \%$ in goal-directed perfusion initiative patients $(P=.008)$; incidences of acute kidney injury stage 1,2 , and 3 were $19.3 \%, 3.4 \%$, and $1.1 \%$ in controls, and $5.7 \%, 3.4 \%$, and $0 \%$ in goal-directed perfusion initiative patients, respectively. Control patients exhibited a larger median percent increase in creatinine from baseline $(27 \%$ vs $10 \%, P<.001)$.

Conclusions: The goal-directed perfusion initiative was associated with reduced acute kidney injury incidence after cardiac surgery in this pilot study. (J Thorac Cardiovasc Surg 2017;153:118-25)

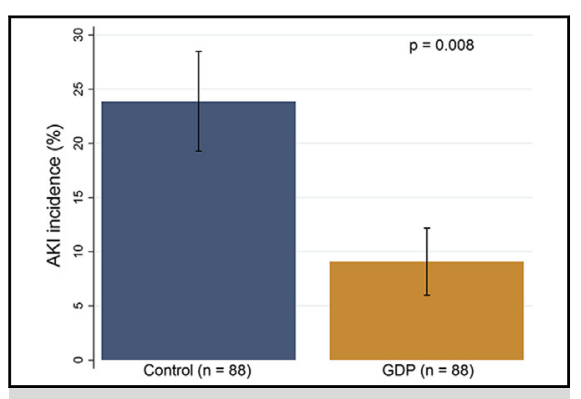

Pilot GDP implementation was associated with reduced AKI after cardiac surgery

\section{Central Message}

Implementation of a pilot GDP initiative was associated with reduced AKI after cardiac surgery.

\section{Perspective}

Recent literature has implicated the conduct of $\mathrm{CPB}$ in the risk of developing AKI after cardiac surgery. For a pilot quality improvement measure, we implemented a bundle of bypassrelated interventions termed "GDP." GDP implementation was associated with a significant reduction in AKI compared with matched controls.

See Editorial Commentary page 126.
From the ${ }^{\mathrm{a}}$ Division of Cardiac Surgery, Department of Surgery, and ${ }^{\mathrm{b}}$ Division of Cardiac Anesthesia, Department of Anesthesiology and Critical Care Medicine, Johns Hopkins University School of Medicine, Baltimore, Md; and ${ }^{\mathrm{c} D e p a r t m e n t}$ of Cardiac Surgery, Vanderbilt University School of Medicine, Nashville, Tenn.

Read at the 96th Annual Meeting of The American Association for Thoracic Surgery, Baltimore, Maryland, May 14-18, 2016.

Received for publication May 22, 2016; revisions received Sept 3, 2016; accepted for publication Sept 7, 2016; available ahead of print Nov 7, 2017.

Address for reprints: Viachaslau Barodka, MD, Division of Cardiac Anesthesia, Department of Anesthesiology and Critical Care Medicine, Johns Hopkins University School of Medicine, 1800 Orleans St, Zayed Tower 8208, Baltimore, MD 21287 (E-mail: vbarodk1@jhmi.edu).

$0022-5223 / \$ 36.00$

Copyright $₫ 2016$ Published by Elsevier Inc. on behalf of The American Association for Thoracic Surgery

http://dx.doi.org/10.1016/j.jtcvs.2016.09.016
Cardiac surgery-associated acute kidney injury (AKI) complicates $20 \%$ to $40 \%$ of cardiac surgical procedures, ${ }^{1,2}$ and even small decrements in glomerular filtration rate (GFR) have been shown to adversely affect patient outcomes. ${ }^{3}$ Traditional risk factors for AKI include age,,${ }^{4,5}$ preoperative renal dysfunction, ${ }^{5,6}$ valve procedures, ${ }^{4,6-8}$ prolonged cardiopulmonary bypass (CPB) times, ${ }^{4-6,8}$ and

Scanning this QR code will take you to supplemental figures for this article. 

Abbreviations and Acronyms
AKI = acute kidney injury
BSA = body surface area
$\mathrm{CPB}=$ cardiopulmonary bypass
$\mathrm{DO} 2=$ oxygen delivery
GDP $=$ goal-directed perfusion
GFR $=$ glomerular filtration rate
ICU = intensive care unit
$\mathrm{IQR}=$ interquartile range
MAP $=$ mean arterial pressure
NIRS = near-infrared spectroscopy
PVD = peripheral vascular disease
RAP $=$ retrograde autologous priming
$\mathrm{ZBUF}=$ zero-balance ultrafiltration

postoperative hypotension. ${ }^{5}$ Many of these risk factors traditionally have been deemed intrinsic to the individual patient and thus unmodifiable. However, more recently, a number of authors have identified modifiable factors associated with CPB that affect AKI risk after cardiac surgery. These have included nadir oxygen delivery (DO2) on $\mathrm{CPB}$, at thresholds ranging from $225 \mathrm{~mL} \mathrm{O} /$ $\mathrm{min} / \mathrm{m}^{2}$ body surface area (BSA) to $272 \mathrm{~mL} \mathrm{O} 2 / \mathrm{min} / \mathrm{m}^{2}$ BSA. ${ }^{9-11}$ To date, however, no clear guidelines or standards of care exist regarding many aspects of CPB. On the basis of these and other findings, in January 2015, several of our perfusionists, anesthesiologists, and surgeons adopted a set of goals as a quality improvement measure during CPB that they believed would reduce the postoperative incidence of AKI (see "Materials and Methods"). We retrospectively sought to determine whether this bundled intervention was associated with reduced AKI incidence after cardiac surgery. The hypothesis of this study was that implementation of the goal-directed perfusion (GDP) initiative would be associated with a reduced AKI incidence within 72 hours of cardiac surgery compared with control patients undergoing surgery using standard CPB management.

\section{MATERIALS AND METHODS \\ Patient Population}

All study procedures were approved by Johns Hopkins' institutional review board, which waived the need for individual patient informed consent. The medical records of patients undergoing cardiac surgery at Johns Hopkins between 2010 and 2015 were reviewed. In addition, records were identified from 100 patients who received CPB according to GDP (Table 1); staffing and training limitations precluded its use in all patients in 2015. We excluded 12 patients from the final analysis who presented with end-stage renal disease on renal replacement therapy, who received nephrotoxic medications, or who underwent unusual or complex cardiac surgical procedures (eg, left ventricular mass excision, aortic arch reconstructions) for whom we could not find appropriate control patients as matches using our algorithm (Table 2). We excluded patients who experienced a significant perioperative event that might plausibly explain
AKI postoperatively (ie, cardiac arrest, massive transfusion $>10$ units of blood, receiving nephrotoxic medications, periods of hypotension with a mean arterial pressure $[\mathrm{MAP}]<60 \mathrm{~mm} \mathrm{Hg}$ for $>15$ minutes in the intensive care unit [ICU] postoperatively, or with signs or symptoms of sepsis).

\section{Data Collection and Definitions}

The primary outcome of our study, AKI, was defined on the basis of the Kidney Disease: Improving Global Outcomes AKI criteria. ${ }^{12}$ However, to restrict our analysis to cardiac surgery-associated AKI, only the first 3 postoperative days of serum creatinine measurements were analyzed (ie, within 72 hours postoperatively). Although this period extends beyond the 48-hour limit advocated by Kidney Disease: Improving Global Outcomes criteria, we chose it because creatinine typically is analyzed using midnight blood samples at Johns Hopkins, and using a 48-hour window would cause us to miss many AKI diagnoses depending on the time surgery was completed and patients were admitted to the ICU. Baseline creatinine was taken within the month before surgery at the patient's preoperative visit. The Cockcroft-Gault equation was used to calculate GFR, with adjustments for body weight and body mass index..$^{13,14}$ Because body weight and habitus can change after surgery and not all patients have reliably documented weights postoperatively, we computed our secondary outcome as simply the maximum percent change in creatinine from baseline during the first 72 postoperative hours. Other secondary outcomes were postoperative cerebrovascular accidents, treatment for pneumonia (ie, antibiotics), postoperative surgical site infections, and 30-day mortalities.

We examined the perfusion records of all patients and calculated their DO2 at each recorded clinical arterial blood sampling according to the following equation: $\mathrm{DO} 2$ in $\mathrm{mL} / \mathrm{min} / \mathrm{m}^{2}$ BSA $=$ pump flow in liters $\times(10 \times$ hemoglobin concentration in grams per deciliter $\times 1.36 \times$ hemoglobin saturation $\%+0.003 \times$ arterial partial pressure of oxygen) $/ \mathrm{m}^{2}$ BSA. The nadir DO2 was taken as the lowest of all calculated values and recorded for each patient.

\section{Anesthesia, Surgery, and Standard (Control) Perfusion Management}

All patients were cared for by the same group of anesthesiologists, surgeons, perfusionists, and intensivists. Anesthesia induction was performed with midazolam, fentanyl, and incremental doses of propofol followed by vecuronium for skeletal muscle relaxation. Anesthesia maintenance was with isoflurane and supplemental doses of fentanyl based on clinical criteria. The patients received propofol 20 to $30 \mu \mathrm{g} / \mathrm{kg} / \mathrm{min}$ for sedation after surgery until the time of tracheal extubation. Nonpulsatile CPB (closed circuits) was established centrally or, on occasion, peripherally for reoperative patients. Lactated Ringer's solution was used to prime the $\mathrm{CPB}$ circuit for all patients. Body temperature was maintained between $28^{\circ} \mathrm{C}$ and $34^{\circ} \mathrm{C}$, except in cases requiring deep hypothermic circulatory arrest when cooling to $18^{\circ} \mathrm{C}$ to $20^{\circ} \mathrm{C}$ was performed. Patients were maintained on isoflurane during CPB. Cold blood cardioplegia in a 4:1 ratio was used for all patients. For control patients undergoing operation between 2010 and 2014, the Sorin Apex oxygenator (LivaNova, London, United Kingdom) was used. A $20-\mu \mathrm{m}$ arterial filter was placed in line for all patients. Anticoagulation was given at an initial dose of $350 \mathrm{U} / \mathrm{kg}$ to achieve a goal activated clotting time of at least 480 seconds. Terumo (Tokyo, Japan) APS1 roller pumps were used for CPB, with the institutional standard pump flow target of 1.8 to $2.2 \mathrm{~L} / \mathrm{min} / \mathrm{m}^{2}$. Phenylephrine $100 \mu \mathrm{g}$ was given parenterally to maintain a MAP of greater than $65 \mathrm{~mm} \mathrm{Hg}$. All patients also had cerebral oximetry monitored via near-infrared spectroscopy (NIRS) throughout each case. Perfusion parameters, such as pump flows and hematocrit, were recorded every 15 minutes, with recalibration of the Terumo CDI Blood Parameter Monitoring System 500 performed every 60 minutes. Arterial blood gas samples also were taken every 15 minutes. Postoperatively, all patients were transported intubated to the cardiac surgery ICU to recover. Except 
TABLE 1. Pilot goal-directed perfusion initiative (goal-directed perfusion guidelines)

\begin{tabular}{|c|c|}
\hline Goal & Intervention \\
\hline Minimize CPB circuit volume & $\begin{array}{l}\text { Use Sorin Inspire oxygenator (LivaNova, London, United Kingdom) } \\
\text { Use } 3 / 8^{\prime \prime} \text { instead of } 1 / 2^{\prime \prime} \text { tubing if possible for venous line } \\
\text { Position CPB circuit closer to OR table }\end{array}$ \\
\hline Avoid "stress" on kidneys & Avoid mannitol in CPB prime \\
\hline Avoid hypovolemia & $\begin{array}{l}\text { Avoid RAP or ensure }<10 \% \text { decrease in MAP or NIRS if using RAP } \\
\text { Return all CPB perfusate to patient }\end{array}$ \\
\hline Ensure tissue oxygenation & $\begin{array}{l}\text { Maintain DO2 }>300 \mathrm{~mL} \mathrm{O} 2 / \mathrm{min} / \mathrm{m}^{2} \mathrm{BSA} \\
\text { Monitor NIRS data to maintain at baseline }\end{array}$ \\
\hline Reduce inflammatory cytokines and coagulation factor consumption & $\begin{array}{l}\text { Use hemoconcentrator and ZBUF } \\
\text { Use heparin drip on } \mathrm{CPB}\end{array}$ \\
\hline Avoid splanchnic vasoconstriction & Minimize phenylephrine use, increase CPB flow first if possible \\
\hline Limit rapidity of rewarming & $\begin{array}{l}\text { Rewarm no faster than } 1^{\circ} \mathrm{C} \text { every } 5 \mathrm{~min} \\
\text { Maintain temperature differential between arterial and venous blood }<3^{\circ} \mathrm{C}\end{array}$ \\
\hline
\end{tabular}

$\overline{C P B}$, Cardiopulmonary bypass; $O R$, operating room; $R A P$, retrograde autologous priming; $M A P$, mean arterial pressure; NIRS, near-infrared spectroscopy; $D O 2$, oxygen delivery; $B S A$, body surface area; $Z B U F$, zero-balance ultrafiltration.

in cases of active bleeding or unusual circumstances as determined by the surgeon, our standard transfusion threshold is a hemoglobin of $8 \mathrm{mg} / \mathrm{dL}$.

\section{Goal-Directed Perfusion Management}

When different from the described standard or control management, the GDP initiative contained the goals listed in Table 1. To minimize hemodilution, we used the low prime volume Sorin Inspire oxygenator (LivaNova, London, United Kingdom), used 3/8-inch instead of 1/2-inch venous lines, and positioned the CPB circuit as close to the operating room table as possible. We sought to minimize mannitol use because its benefit is unproven, ${ }^{15,16}$ and it can mask real-time urine output as a marker of renal perfusion. In an attempt to avoid episodes of hypovolemic shock, we restricted retrograde autologous priming (RAP) use to a $10 \%$ decrease in MAP or NIRS readings, because such decreases have been associated with adverse outcomes. ${ }^{17,18}$ Once the patient was on $\mathrm{CPB}$, we sought to maintain DO2 greater than $300 \mathrm{~mL} \mathrm{O} 2 / \mathrm{min} / \mathrm{m}^{2}$ in keeping with the findings by our group and others about the importance of nadir DO2 and its association with $\mathrm{AKI}^{9-11}$; we chose this conservative target of $300 \mathrm{~mL}$ $\mathrm{O} 2 / \mathrm{min} / \mathrm{m}^{2}$ to remain safely above the published risk thresholds of 225 to $272 \mathrm{~mL} \mathrm{O} 2 / \mathrm{min} / \mathrm{m}^{2}$. The perfusion staff targeted this range by increasing pump flows, as opposed to blood product transfusion. Given the known inflammatory effects of CPB and their potentially deleterious role in affecting renal function, ${ }^{19-21}$ but also the emergence of literature documenting the association of AKI and continuous ultrafiltration, ${ }^{22}$ we used zero-balance ultrafiltration (ZBUF) in GDP patients as a means of mitigating CPB's inflammatory effects. ZBUF also has been shown to be protective against cardiac surgery-associated $\mathrm{AKI}$ in a recent randomized trial. ${ }^{23}$ ZBUF was initiated on CPB initiation at a rate of 4 to $6 \mathrm{~L} /$ hour of volume exchange with a transmembrane pressure of 350 to $450 \mathrm{~mm} \mathrm{Hg}$ and a hemoconcentrator with a molecular cutoff of $65 \mathrm{kDa}$; lactated Ringers' solution was used as replacement fluid, and a buffering agent was not used. We used a heparin drip to prevent consumptive coagulopathy, prevent excessive inflammation, and maintain higher hemoglobin values postbypass. ${ }^{24}$ By following the same initial bolus of $350 \mathrm{U} / \mathrm{kg}$ as in control patients, heparin was given continuously at a rate of (the total calculated dose) divided by 3 infused per hour and given until crossclamp removal. Although it was counterintuitive, we sought to minimize vasopressor use out of concerns that it may have adverse effects on AKI rates. ${ }^{9}$ Finally, we sought to limit the rate of rewarming after bypass, because high rewarming rates have been associated with neurocognitive dysfunction, increased glial fibrillary acid protein release, and potentially AKI. ${ }^{25,26}$ The rate of rewarming was limited to $1^{\circ} \mathrm{C}$ every 5 minutes on bypass,

TABLE 2. Excluded patients: Patients who received care on the goal-directed perfusion protocol but were excluded from the final analysis

\begin{tabular}{|c|c|c|c|c|c|}
\hline Patient & Age, $y$ & Procedure & Reason for exclusion & Baseline $\mathbf{C r}$ & Postoperative peak $\mathrm{Cr}<72 \mathrm{~h}$ \\
\hline 1 & 50 & LV mass excision & No comparable procedure & 1.5 & 1.4 \\
\hline 2 & 62 & $\mathrm{CABG} \times 4$ & $\begin{array}{l}\text { Preoperative } \mathrm{ECMO} \text { and } \mathrm{AKI} \\
\text { requiring } \mathrm{CVVHD}\end{array}$ & - & - \\
\hline 3 & 49 & $\mathrm{CABG} \times 2$ & Preoperative ESRD & - & - \\
\hline 4 & 86 & $\mathrm{CABG} \times 3$ & No match available & 1.3 & 2.3 \\
\hline 5 & 54 & OHT & Tacrolimus toxicity & 1.5 & 3.4 \\
\hline 6 & 77 & Robotic tricuspid valve repair & No match available & 1.3 & 1.5 \\
\hline 7 & 51 & AVR & No match available & 1.3 & 1.3 \\
\hline 8 & 77 & $\mathrm{CABG} \times 4$ & $\begin{array}{l}\text { Reoperation excluded (index } \\
\text { CABG was included) }\end{array}$ & 1.4 & 1.6 \\
\hline 9 & 76 & $\mathrm{CABG} \times 3$ & Preoperative ESRD & - & - \\
\hline 10 & 64 & $\mathrm{CABG} \times 3$ & No match available & 1.1 & 1.0 \\
\hline 11 & 78 & $\mathrm{CABG} \times 3$ and LV thrombectomy & $\mathrm{VF}$ arrest on transfer from OR to ICU & 1.6 & 1.4 \\
\hline 12 & 56 & $\mathrm{CABG} \times 3$ & Preoperative ESRD & - & - \\
\hline
\end{tabular}

Serum creatinine in milligrams/deciliter. $C r$, Creatinine; $L V$, left ventricle; $C A B G$, coronary artery bypass grafting; $E C M O$, extracorporeal membrane oxygenation; $A K I$, acute kidney injury; $C V V H D$, continuous venovenous hemodialysis; ESRD, end-stage renal disease on dialysis; $O H T$, orthotopic heart transplantation; $A V R$, aortic valve replacement; $V F$, ventricular fibrillation; $O R$, operating room; $I C U$, intensive care unit. 
with arterial temperatures not allowed to exceed $36.5^{\circ} \mathrm{C}$ unless specifically requested. At the end of $\mathrm{CPB}$, all remaining perfusate was processed via an intraoperative blood salvage system (Cell Saver, Haemonetics, Braintree, Mass) and then infused into the patient.

Compliance with GDP guidelines was expected for the following criteria: use of the Sorin Inspire oxygenator, 3/8" venous line use, avoidance of RAP, NIRS use, ZBUF use, and rewarming criteria, because these were straightforward guidelines. However, deviation from other criteria were not unexpected on the basis of the clinical situation. When possible, adherence to these goals was assessed by review of CPB records for GDP patients and controls, with the purpose of determining whether GDP patients' treatment trended toward the stated protocol goals. However, data were analyzed in an intention-to-treat fashion (ie, all patients in whom GDP was attempted were considered to have received the full bundle for the purposes of outcomes analysis, regardless of adherence to GDP goals).

Postoperatively, all patients were transported to the ICU intubated to recover. Epinephrine infusions were used whenever inotropic support was required in patients, with a goal MAP greater than 65 . The ICU staff were unaware of the intraoperative perfusion management strategy used on individual patients.

\section{Statistical Analysis}

A power calculation demonstrated that on the basis of an estimated AKI incidence of $30 \%$ in controls ${ }^{27}$ versus $10 \%$ in GDP patients, alpha of 0.05 , and power of $80 \%, 2$ groups of 72 patients would be required. We emphasize that this pilot study was underpowered to detect differences in the expected rates of our secondary outcomes of cerebrovascular accidents, surgical site infections, and mortality. Patients undergoing GDP were matched with controls undergoing $\mathrm{CPB}$ with standard conduct using propensity scores calculated on the basis of the following variables: age; race; BSA; gender; history of hypertension, diabetes, or peripheral vascular disease (PVD); preoperative GFR; left ventricular ejection fraction; presence of a preoperative intra-aortic balloon pump; presentation in cardiogenic shock; urgent or emergency operative status; procedure type (including coronary artery bypass, aortic valve replacement, and ascending aortic procedures); year of surgery; and CPB duration (time). The same exclusion criteria described were applied to controls (including MAP $>60 \mathrm{~mm}$ Hg postoperatively). Note that because of our inability to extensively review the charts of thousands of patients, such criteria were applied after the generation of matches, with repeated matching performed as necessary. The balancing property was tested and found to be satisfied. After score calculation, we performed 1:1 matching using a greedy nearest-neighbor algorithm ${ }^{28}$ without replacement of the remaining $88 \mathrm{GDP}$ patients to 88 control patients using a caliper of $20 \%$ of the logit of the score's standard deviation (see "Results") (Table 3 and Figures E1 and E2).

Data are expressed as mean \pm standard error or median (interquartile range [IQR] when not normally distributed). For propensity-matched variables, absolute standardized differences also are given as an index of imbalance. Continuous variables were analyzed with paired Student $t$ tests or rank-sum tests, and categoric variables were analyzed with the chi-square or Fisher exact test. Outcomes were assessed using McNemar's test to account for the matched nature of the data. STATA SE 12.0 (StataCorp LP, College Station, Tex) was used for all statistical analyses.

\section{RESULTS}

We analyzed the records of 5225 patients undergoing cardiac surgery on CPB at Johns Hopkins between 2010 and 2015 along with 88 GDP patients undergoing surgery in 2015 (Figure 1). The data analysis included 88 patients who received CPB conducted according to GDP guidelines and 88 matched historical and contemporaneous control patients undergoing cardiac surgery at Johns Hopkins between 2010 and 2015. Patients were well matched across most baseline and operative variables, and the propensity score's c-statistic was 0.71 (Table 3). Of note, there was a trend in GDP patients toward higher risks of renal failure $(3.2 \%$ vs $4.6 \%, P=.06)$, operative mortality $(1.4 \%$ vs $2.1 \%, P=.08)$, and combined morbidity/mortality $(13.3 \%$ vs $16.3 \%, P=.07)$. Cardiac catheterization within 1 month before surgery was more common in GDP patients compared with controls $(76.1 \%$ vs $62.5 \%, P=.05)$, and these occurred at similar preoperative time points (median 4 days preoperatively [IQR, 2-7] in controls and 4 days [IQR, 3-8] in GDP patients, $P=.68$ ). The median contrast volume used was similar between both groups (controls, $50 \mathrm{~mL}$ vs GDP, $57 \mathrm{~mL}, P=.95$ ).

Achievement of GDP perfusion goals is shown in Table 4. Nadir DO2 on CPB was lower in controls than GDP patients $\left(240\right.$ vs $302 \mathrm{~mL} / \mathrm{min} / \mathrm{m}^{2}$ BSA, $\left.P<.001\right)$, and this appeared to be driven by higher pump flows (1.9 vs $\left.2.4 \mathrm{~L} / \mathrm{min} / \mathrm{m}^{2}, P<.001\right)$ as opposed to differences in nadir hemoglobin concentrations on CPB (9.0 vs 8.7, $P=.46)$. Although we cannot report an absolute compliance rate given that some of the GDP guidelines were not hard-and-fast rules, we note that all GDP patients received the Sorin Inspire oxygenator, no RAP, NIRS monitoring, ZBUF, and met rewarming criteria. However, $17.1 \%$ of GDP patients still received mannitol in their pump primes, and we could only determine conclusively that $50.6 \%$ of GDP patients received heparin infusions (as opposed to intermittent dosing, because documentation was unclear in many cases). Of note, $9.5 \%$ of control and $14.8 \%$ of GDP patients received blood as part of the CPB pump prime $(P=.35)$; the median hematocrit of patients receiving PRBC in the pump prime was 31.5 (IQR, 30-33.5) compared with 39 (IQR, 36-42) for patients not receiving blood in the pump prime $(P=.003)$.

Postoperatively, patients in both groups were transferred from the operating room to the ICU on the same epinephrine infusion doses (controls, median $0.03 \mu \mathrm{g} / \mathrm{kg} / \mathrm{min}$ [IQR, $0-0.05$ ] vs GDP, 0.03 [IQR, 0-0.05], $P=.26$ ). By the end of postoperative day 1 , the majority of patients had been weaned off vasopressors (median epinephrine doses 0 [IQR, $0-0$ ] in both groups, $P=.25$ ).

The incidence of AKI stage 1 or greater was higher in controls than GDP patients $(23.9 \%$ vs $9.1 \%, P=.008)$ (Table 5). Although the degree of AKI was predominantly AKI stage 1 (ie, $50 \%-100 \%$ increase in serum creatinine from baseline), this difference also persisted when analyzing the data across all 3 stages of AKI (chi-square $P=.03$ ). The median percent increase in serum creatinine over the first 72 postoperative hours was higher in controls $(27 \%$ vs $10 \%, P<.001)$. In a subgroup analysis, we also compared changes in creatinine from baseline among only patients with preoperative GFR less than $90 \mathrm{~mL} / \mathrm{min}$ and 
TABLE 3. Preoperative and operative characteristics of controls and goal-directed perfusion patients

\begin{tabular}{|c|c|c|c|c|c|c|c|c|}
\hline Matching variables & All patients & $\begin{array}{c}\text { Goal-directed } \\
\text { perfusion patients }\end{array}$ & $\begin{array}{c}P \\
\text { value }\end{array}$ & SDIFF & $\begin{array}{c}\text { Historical } \\
\text { controls }\end{array}$ & $\begin{array}{c}\text { Goal-directed } \\
\text { perfusion patients }\end{array}$ & $\begin{array}{c}P \\
\text { value }\end{array}$ & SDIFF \\
\hline $\mathrm{n}$ & 5225 & 88 & - & - & 88 & 88 & - & - \\
\hline Mean age \pm SD (y) & $62 \pm 15$ & $64 \pm 12$ & .20 & 0.14 & $61 \pm 13$ & $64 \pm 12$ & .12 & 0.21 \\
\hline Mean BSA $\left(\mathrm{m}^{2}\right)$ & $2.1 \pm 0.1$ & $2.1 \pm 0.3$ & .38 & 0.13 & $2.1 \pm 0.2$ & $2.1 \pm 0.3$ & .28 & 0.16 \\
\hline Male gender \% (n) & $66.3(3466)$ & $76.1(67)$ & .05 & 0.20 & $80.7(71)$ & $76.1(67)$ & .46 & -0.15 \\
\hline African-American race & $14.4(751)$ & $10.2(9)$ & .27 & -0.10 & $14.8(13)$ & $10.2(9)$ & .36 & -0.05 \\
\hline Hypertension & $69.2(3616)$ & $72.7(64)$ & .48 & 0.04 & $70.5(62)$ & $72.7(64)$ & .74 & 0.06 \\
\hline Diabetes & $28.4(1484)$ & $23.9(21)$ & .35 & -0.10 & $18.2(16)$ & $23.9(21)$ & .36 & 0.21 \\
\hline PVD & $7.7(402)$ & $3.4(3)$ & .13 & -0.21 & $9.1(8)$ & $3.4(3)$ & .12 & -0.24 \\
\hline $\begin{array}{l}\text { Mean preoperative } \\
\text { GFR } \mathrm{mL} / \mathrm{min} \pm \mathrm{SD}\end{array}$ & $80 \pm 34$ & $83 \pm 55$ & .30 & 0.07 & $90 \pm 35$ & $83 \pm 55$ & .34 & -0.14 \\
\hline \multicolumn{9}{|l|}{ Preoperative GFR stage } \\
\hline $0(>120 \mathrm{~mL} / \mathrm{min})$ & $11.5(601)$ & $11.4(10)$ & .66 & -0.04 & $20.5(18)$ & $11.4(10)$ & .49 & 0.27 \\
\hline $1(90-120 \mathrm{~mL} / \mathrm{min})$ & $22.3(1166)$ & $22.7(20)$ & & & $21.6(19)$ & $22.7(20)$ & & \\
\hline $2(60-90 \mathrm{~mL} / \mathrm{min})$ & $36.6(1911)$ & $43.2(38)$ & & & $43.2(38)$ & $43.2(38)$ & & \\
\hline $3(30-60 \mathrm{~mL} / \mathrm{min})$ & $25.6(1338)$ & $18.2(16)$ & & & $12.5(11)$ & $18.2(16)$ & & \\
\hline $4-5(0-30 \mathrm{~mL} / \mathrm{min})$ & $4.0(199)$ & $4.5(4)$ & & & $2.3(2)$ & $4.5(4)$ & & \\
\hline Mean $\mathrm{EF} \pm \mathrm{SD}$ & $51 \pm 15$ & $54 \pm 13$ & .07 & 0.18 & $54 \pm 10$ & $54 \pm 13$ & .81 & -0.06 \\
\hline IABP preoperatively & $9.4(490)$ & $9.1(8)$ & .93 & -0.06 & $6.8(6)$ & $9.1(8)$ & .58 & 0.07 \\
\hline Presented in cardiogenic shock & $2.1(104)$ & $1.1(1)$ & .52 & -0.08 & 0 & $1.1(1)$ & .32 & 0.15 \\
\hline Urgent/emergency operative status & $29.6(1544)$ & $53.4(47)$ & $<.001$ & 0.48 & $50.0(44)$ & $53.4(47)$ & .65 & 0.09 \\
\hline Coronary artery bypass in OR & $45.1(2357)$ & $72.7(64)$ & $<.001$ & 0.54 & $72.7(64)$ & $72.7(64)$ & 1.00 & 0.03 \\
\hline Aortic valve replacement & $17.2(896)$ & $19.3(17)$ & .59 & -0.01 & $22.7(20)$ & $19.3(17)$ & .58 & -0.11 \\
\hline Ascending aortic procedure & $2.2(109)$ & $6.8(6)$ & .005 & 0.23 & $4.6(4)$ & $6.8(6)$ & .52 & 0.09 \\
\hline Mean bypass time $(\min ) \pm \mathrm{SD}$ & $116 \pm 55$ & $114 \pm 50$ & .68 & -0.04 & $109 \pm 49$ & $114 \pm 50$ & .55 & 0.11 \\
\hline Mean crossclamp time $(\mathrm{min}) \pm \mathrm{SD}$ & $74 \pm 34$ & $75 \pm 35$ & .76 & 0.03 & $77 \pm 37$ & $75 \pm 35$ & .76 & -0.05 \\
\hline Mean difference $(\min ) \pm \mathrm{SD}$ & $42 \pm 33$ & $39 \pm 21$ & .33 & -0.12 & $33 \pm 26$ & $39 \pm 21$ & .11 & 0.25 \\
\hline
\end{tabular}

Note that procedure categories are not necessarily mutually exclusive. Bold indicates statistical significance. $S D I F F$, Standardized differences; $S D$, standard deviation; $B S A$, body surface area; $P V D$, peripheral vascular disease; GFR, glomerular filtration rate; $E F$, ejection fraction; IABP, intra-aortic balloon pump; $O R$, operating room.

less than $60 \mathrm{~mL} / \mathrm{min}$, and found that significant differences in median serum creatinine increases persisted (GFR $<90$, $22 \%$ vs $9 \%, P=.001$; GFR $<60,40 \%$ vs $9 \%, P=.04)$, albeit in smaller groups of patients (Table 5). Only 1 control patient (and no GDP patients) required hemodialysis. For both groups, the median time to peak creatinine was

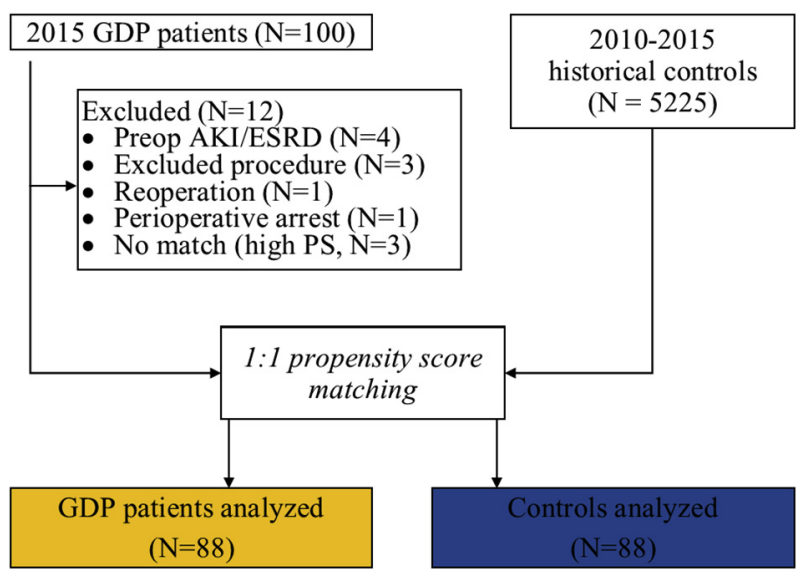

FIGURE 1. Flow chart of patients included and excluded. GDP, Goal-directed perfusion; $A K I$, acute kidney injury; ESRD, end-stage renal disease; $P S$, propensity score.
2 days (IQR, 2-3 for both groups; $P=.65$ ). Although our study was not designed to address trends over time, we note that the difference in median percent creatinine change from baseline between groups appeared graphically to persist through postoperative day 5 (Figure 2).

In light of the modest imbalance between matched GDP and control groups observed for the variables of PVD and preoperative GFR stage, we performed a sensitivity analysis looking at these patients. In regard to PVD, 3 of 8 control patients with PVD developed AKI (2 had stage 1 and 1 had stage 2), whereas 1 of 3 GDP patients with PVD developed AKI (1 had stage 1). For preoperative renal function, 13 control patients and 20 GDP patients had preoperative GFR stage 3 or greater. A total of 5 of 13 of these controls developed AKI (4 had stage 1 and 1 had stage 2), whereas only 2 of 20 of these GDP patients developed AKI (1 had stage 1 and 1 had stage 2). If one was to simply exclude all patients with PVD or preoperative GFR stages of 3 or greater from the final analysis, then the incidence of AKI was $19.7 \%(14 / 71)$ in controls versus $9.0 \%(6 / 67)$ in GDP patients $(P=.07)$. Stage 1,2 , and 3 AKI were present in 12,1 , and 1 control patients versus 4,2 , and 0 GDP patients, respectively $(P=.15)$. 
TABLE 4. Assessment of perfusion goals achieved in controls and goal-directed perfusion patients

\begin{tabular}{|c|c|c|c|}
\hline & Controls & Goal-directed perfusion patients & $P$ value \\
\hline Crystalloid prime volume (median $\mathrm{mL}, \mathrm{IQR}$ ) & $650(500-1000)$ & $800(500-1000)$ & .28 \\
\hline PRBC in prime $(\%, n)$ & $9.5(8)$ & $14.8(13)$ & .35 \\
\hline Received any mannitol in prime $(\%, \mathrm{n})$ & $91.7(77 / 84)$ & $17.1(15 / 88)$ & $<.001$ \\
\hline Total phenylephrine administered (median mg \pm IQR) & $1.5(0.7-3.25)$ & $0.65(0.2-2.4)$ & .001 \\
\hline Heparin drip used in OR & 0 & $50.6(45 / 88)$ & $<.001$ \\
\hline Nadir temperature on $\mathrm{CPB}\left({ }^{\circ} \mathrm{C} \pm \mathrm{SD}\right)$ & $32 \pm 3$ & $33 \pm 3$ & .02 \\
\hline Hemoconcentrator used $(\%, \mathrm{n})$ & $46.4(39 / 84)$ & $98.9(87 / 88)$ & $<.001$ \\
\hline Volume exchanged with hemoconcentrator (median $\mathrm{L} \pm \mathrm{IQR}$ ) & $2.0(1.2-3.0)$ & $6.0(4.3-9.0)$ & $<.001$ \\
\hline Nadir $\mathrm{Hb}$ on $\mathrm{CPB}(\mathrm{mg} / \mathrm{dL} \pm \mathrm{SD})$ & $9.0 \pm 1.8$ & $8.7 \pm 2.0$ & .46 \\
\hline Nadir pump flow $/ \mathrm{m}^{2}\left(\mathrm{~L} / \mathrm{min} / \mathrm{m}^{2} \mathrm{BSA} \pm \mathrm{SD}\right)$ & $1.9 \pm 0.3$ & $2.4 \pm 0.4$ & $<.001$ \\
\hline Nadir DO2 $\left(\mathrm{mL} \mathrm{O}_{2} / \mathrm{min} / \mathrm{m}^{2} \mathrm{BSA} \pm \mathrm{SD}\right)$ & $240 \pm 64$ & $302 \pm 62$ & $<.001$ \\
\hline
\end{tabular}

Complete perfusion records were available for 84 of 88 historical controls and 88 of 88 GDP patients. Bold indicates statistical significance. IQR, Interquartile range; $P R B C$, packed red blood cell; $O R$, operating room; $C P B$, cardiopulmonary bypass; $S D$, standard deviation; $H b$, hemoglobin; $D O 2$, oxygen delivery; $B S A$, body surface area.

Patients in both control and GDP groups spent similar lengths of time in the ICU postoperatively (32 hours [24-62] vs 31 hours [23-53], $P=.68$ ) and had similar hospital lengths of stay ( 9 days [6-13] vs 8 days [6-12], $P=.59)$. There were no differences between controls and GDP cases in the rates of postoperative cerebrovascular accidents $(2.3 \%$ vs $2.3 \%, P=1.00)$, treatment for pneumonia $(8.0 \%$ vs $10.2 \%, P=.60)$, any surgical site infections $(0 \%$ vs $1.1 \%, P=.32)$, or 30 -day mortality $(1.1 \%$ vs $0 \%, P=.32)$.

\section{DISCUSSION}

AKI continues to be one of the most common complications of cardiac surgery, and even stage 1 AKI has been associated with elevated in-hospital mortality rates. ${ }^{2,3,29}$ Within our practice, the ongoing problem of AKI prompted a search for ways to mitigate AKI rates, culminating in the GDP pilot initiative. In the present study, we found that pilot implementation of our GDP initiative was associated with a reduced incidence of AKI and a reduction in the postoperative creatinine increase that many patients undergoing cardiac surgery experience. This was true despite our relatively conservative matching process, which selected controls who trended toward lower Society of Thoracic Surgeons predicted risks of renal failure, operative mortality, and combined morbidity and mortality.

The principal inspiration for our study was data published by Ranucci and colleagues, ${ }^{11}$ de Somer and colleagues, ${ }^{10}$ and our group, ${ }^{9}$ suggesting that nadir DO2 on CPB less than 225 to $272 \mathrm{~mL} \mathrm{O} / \mathrm{min} / \mathrm{m}^{2}$ is associated with AKI. Although this pilot study of a bundled intervention cannot address the individual effect of any one GDP component, we would note that our perfusionists were able to achieve convincingly higher nadir DO2 levels, and the mechanism appeared to be via higher CPB flow rates. We note that because our perfusion records are only captured every 15 minutes by hand, we did not attempt area under the curve type computations to assess whether overall DO2 was improved in GDP patients, but we hope to address this in the future as we transition to a new electronic medical record.

In addition to nadir $\mathrm{DO} 2$, accumulating evidence on the use of ultrafiltration in cardiac surgery also led us to include ZBUF in our initiative. Although ultrafiltration has not been convincingly associated with improved outcomes in adult cardiac surgery, it can reduce cytokine and adhesion molecule levels ${ }^{23,30}$ and has been suggested to improve

TABLE 5. Outcomes of control and goal-directed perfusion patients

\begin{tabular}{|c|c|c|c|}
\hline & $\begin{array}{l}\text { Controls } \\
(\mathbf{n}=\mathbf{8 8})\end{array}$ & Goal-directed perfusion patients $(n=88)$ & $P$ value \\
\hline Incidence of $\mathrm{AKI}(50 \%$ increase from base) & $23.9(21)$ & $9.1(8)$ & .008 \\
\hline AKIN 0 (no AKI) & $76.1(67)$ & $90.9(80)$ & .03 \\
\hline AKI stage $1(50 \%-100 \%$ or $\geq 0.3$ increase $)$ & $19.3(17)$ & $5.7(5)$ & \\
\hline AKI stage $2(100 \%-200 \%$ increase $)$ & $3.4(3)$ & $3.4(3)$ & \\
\hline AKI stage 3 ( $>200 \%$ increase or HD) & $1(1.1)$ & 0 & \\
\hline Median \% Cr increase from baseline (IQR) & $27(11-48)$ & $10(0-27)$ & $<.001$ \\
\hline Only patients with preoperative GFR $<90 \mathrm{~mL} / \mathrm{min}$ (No. of pts) & 51 & 58 & \\
\hline Median \% Cr increase from baseline (IQR) & $22(8-45)$ & $9(0-27)$ & .001 \\
\hline Only patients with preoperative GFR $<60 \mathrm{~mL} / \mathrm{min}$ (No. of pts) & 13 & 20 & \\
\hline Median \% Cr increase from baseline (IQR) & $40(7-57)$ & $9(-5$ to 28$)$ & .04 \\
\hline
\end{tabular}

AKI, Acute kidney injury; $A K I N$, Acute Kidney Injury Network; $H D$, hemodialysis; $C r$, creatinine; $I Q R$, interquartile range; GFR, glomerular filtration rate; pts, patients. 


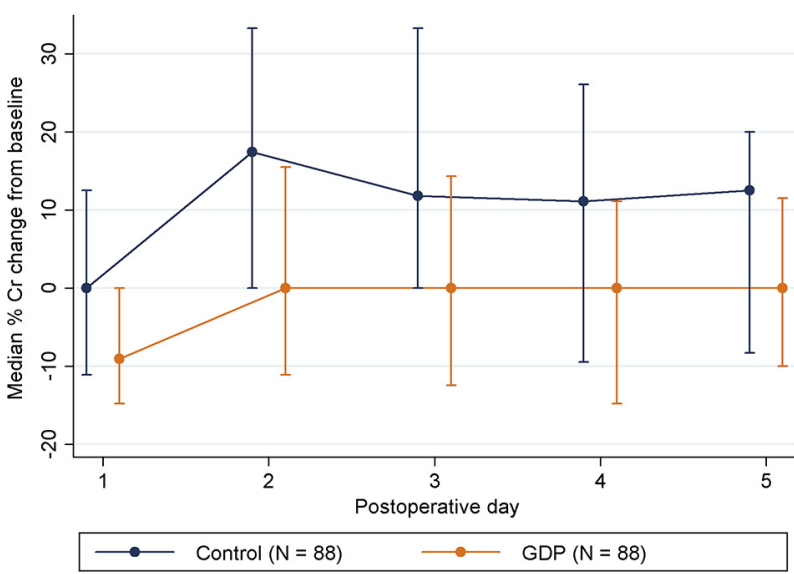

FIGURE 2. Graph showing median percent creatinine changes from baseline, by postoperative day. Error bars denote IQR. Note that because these values are measured daily, they differ from our defined outcomes in the text. Serum creatinine in milligrams/deciliters. $\mathrm{Cr}$, Creatinine; $G D P$, goal-directed perfusion.

pulmonary and left ventricular function in children. ${ }^{31}$ However, the use of conventional ultrafiltration has been associated with AKI in the work of Paugh and colleagues. ${ }^{22}$ This appears to be due to overzealous volume removal, because Paugh and colleagues found that increasing continuous ultrafiltration volumes were associated with a higher AKI risk in patients with GFR less than 99.6. ZBUF is by definition volume neutral, but in theory affords the advantages of reducing inflammatory mediators, in addition to limited data suggesting diminished morbidity in both pediatric and adult patients. ${ }^{30-33}$ For these reasons, we chose to include ZBUF in our GDP, but further study is clearly needed.

We also want to highlight that goal compliance was imperfect in this pilot quality improvement initiative. In examining GDP adherence, we note that prime volumes appear not to have changed despite using an oxygenator with a significantly lower prime volume. This may be because a decrease in RAP volumes under GDP offsets the newer Sorin Inspire oxygenators' reduced prime volumes. Two additional parameters seemed to have poor compliance. First, $17 \%$ of GDP patients continued to receive mannitol in their pump primes, despite clear GDP guidelines to the contrary. This may reflect inadequate staff education regarding the GDP parameters, which is always a challenge in implementing quality improvement initiatives. Likewise, we could only find evidence that $50 \%$ of GDP patients received continuous heparin infusions in the operating room. Inadequate documentation in our electronic anesthesia data recording system seems to have played a role in this, although compliance was undoubtedly less than $100 \%$, again due to inadequate education about the GDP. Although the GDP did not require any additional staffing, staff turnover posed a challenge to its implementation because it seemed unwise to train new staff in the GDP initiative before traditional perfusion methods were mastered. Moreover, any practice change requires the "buy-in" of all staff for successful implementation, and the considered opinions of many excellent and experienced staff can complicate this process. Nonetheless, we were encouraged that despite imperfect compliance, our attempts to standardize practice seem to have been associated with reductions in AKI incidence after cardiac surgery. In the modern era of medicine, nonstandardized practices represent "red flags," and we hope to have made at least a first effort in improve our perfusion practices.

\section{Study Limitations}

Our study has several key limitations. First is the lack of randomization, which precludes the drawing of definite conclusions about the efficacy of our GDP protocol and leaves us vulnerable to a Hawthorne effect. Moreover, many patients receiving GDP had normal renal function and therefore stood to benefit little from practices that may show a larger effect in those with a higher preoperative probability of developing cardiac surgery-associated AKI. Although some authors have noted that even mild decrements in renal function are associated with worse outcomes after cardiac surgery, the clinical significance of the AKI we witnessed was, for the most part, minor, and only 1 patient in the control group and no GDP patients required dialysis. Our use of an intention-to-treat analysis also may have obscured the true salutary effects of the GDP because protocol compliance was imperfect. The standard conduct of CPB often varied between individual care teams, and we are limited in determining which intervention was most effective aside from hypotheses (eg, which may arise from differences noted in Table 4). We are unable to assess the importance of each individual goal, because this approach merely tests a bundled intervention. We would highlight that although the GDP cases had higher Society of Thoracic Surgeons predicted risks of renal failure compared with controls, we seem to have modestly reduced their rate of AKI after cardiac surgery. Our actual power to detect the observed differences is $75.8 \%$, in line with our preliminary calculations. Even if our observed effect merely reflects improved staff awareness about the conduct of perioperative care, we are encouraged at the prospect of improving outcomes for our patients. Moreover, the GDP is relatively straightforward to implement, and our perfusion staff estimate the additional cost on a per-patient basis at $\$ 200$ to $\$ 300$, if not less.

\section{CONCLUSIONS}

The bundle of interventions in our GDP pilot quality improvement measure seem to be associated with a reduced 
incidence of AKI and milder increases in postoperative serum creatinine. Further randomized trials undoubtedly are warranted to confirm these preliminary results and to assess the effect of such measures in patients at greatest risk for cardiac surgery-associated AKI preoperatively, such as older patients who present with impaired renal function.

\section{Conflict of Interest Statement}

Authors have nothing to disclose with regard to commercial support.

Dr Magruder is the Irene Piccinini Investigator in Cardiac Surgery at Johns Hopkins. Dr Crawford is the Sharp Fellow in Cardiac Surgical Research at Johns Hopkins.

\section{References}

1. Chang TI, Leong TK, Boothroyd DB, Hlatky MA, Go AS. Acute kidney injury after CABG versus PCI: an observational study using 2 cohorts. $J$ Am Coll Cardiol. 2014;64:985-94.

2. Provenchere S, Plantefeve G, Hufnagel G, Vicaut E, De Vaumas C, Lecharny JB, et al. Renal dysfunction after cardiac surgery with normothermic cardiopulmonary bypass: incidence, risk factors, and effect on clinical outcome. Anesth Analg. 2003;96:1258-64.

3. Elmistekawy E, McDonald B, Hudson C, Ruel M, Mesana T, Chan V, et al. Clinical impact of mild acute kidney injury after cardiac surgery. Ann Thorac Surg. 2014;98:815-22.

4. Sirvinskas E, Andrejaitiene J, Raliene L, Nasvytis L, Karbonskiene A, Pilvinis V, et al. Cardiopulmonary bypass management and acute renal failure: risk factors and prognosis. Perfusion. 2008;23:323-7.

5. Suen WS, Mok CK, Chiu SW, Cheung KL, Lee WT, Cheung D, et al. Risk factors for development of acute renal failure (ARF) requiring dialysis in patients undergoing cardiac surgery. Angiology. 1998;49:789-800.

6. Mangos GJ, Brown MA, Chan WY, Horton D, Trew P, Whitworth JA. Acute renal failure following cardiac surgery: incidence, outcomes and risk factors. Aust N Z J Med. 1995;25:284-9.

7. Grayson $\mathrm{AD}$, Khater M, Jackson M, Fox MA. Valvular heart operation is an independent risk factor for acute renal failure. Ann Thorac Surg. 2003;75: $1829-35$

8. Tuttle KR, Worrall NK, Dahlstrom LR, Nandagopal R, Kausz AT, Davis CL. Predictors of ARF after cardiac surgical procedures. Am J Kidney Dis. 2003; 41:76-83.

9. Magruder JT, Dungan SP, Grimm JC, Harness HL, Wierschke C, Castillejo S, et al. Nadir oxygen delivery on bypass and hypotension increase acute kidney injury risk after cardiac operations. Ann Thorac Surg. 2015;100:1697-703.

10. de Somer F, Mulholland JW, Bryan MR, Aloisio T, Van Nooten GJ, Ranucci M. $\mathrm{O} 2$ delivery and $\mathrm{CO} 2$ production during cardiopulmonary bypass as determinants of acute kidney injury: time for a goal-directed perfusion management? Crit Care. 2011;15:R192.

11. Ranucci M, Romitti F, Isgro G, Cotza M, Brozzi S, Boncilli A, et al. Oxygen delivery during cardiopulmonary bypass and acute renal failure after coronary operations. Ann Thorac Surg. 2005;80:2213-20.

12. Okusa MD, Davenport A. Reading between the (guide)lines-the KDIGO practice guideline on acute kidney injury in the individual patient. Kidney Int. 2014;85: 39-48.

13. Brown DL, Masselink AJ, Lalla CD. Functional range of creatinine clearance for renal drug dosing: a practical solution to the controversy of which weight to use in the Cockcroft-Gault equation. Ann Pharmacother. 2013;47: 1039-44.

14. Winter MA, Guhr KN, Berg GM. Impact of various body weights and serum creatinine concentrations on the bias and accuracy of the Cockcroft-Gault equation. Pharmacotherapy. 2012;32:604-12.

15. Haydock MD, Kruger C, Willcox T, Haydock DA. Does removing Mannitol and Voluven from the priming fluid of the cardiopulmonary bypass circuit have clinical effects? J Extra Corpor Technol. 2014;46:77-83.
16. Smith MN, Best D, Sheppard SV, Smith DC. The effect of mannitol on rena function after cardiopulmonary bypass in patients with established renal dysfunction. Anaesthesia. 2008;63:701-4.

17. Levin MA, Lin HM, Castillo JG, Adams DH, Reich DL, Fischer GW. Early on-cardiopulmonary bypass hypotension and other factors associated with vasoplegic syndrome. Circulation. 2009;120:1664-71.

18. Ono M, Brady K, Easley RB, Brown C, Kraut M, Gottesman RF, et al. Duration and magnitude of blood pressure below cerebral autoregulation threshold during cardiopulmonary bypass is associated with major morbidity and operative mortality. J Thorac Cardiovasc Surg. 2014;147:483-9.

19. Cremer J, Martin M, Redl H, Bahrami S, Abraham C, Graeter T, et al. Systemic inflammatory response syndrome after cardiac operations. Ann Thorac Surg. 1996;61:1714-20

20. Czerny M, Baumer H, Kilo J, Lassnigg A, Hamwi A, Vukovich T, et al. Inflammatory response and myocardial injury following coronary artery bypass grafting with or without cardiopulmonary bypass. Eur J Cardiothorac Surg. 2000;17:737-42

21. Donnahoo KK, Meng X, Ayala A, Cain MP, Harken AH, Meldrum DR. Early kidney TNF-alpha expression mediates neutrophil infiltration and injury after renal ischemia-reperfusion. Am J Physiol. 1999;277:R922-9.

22. Paugh TA, Dickinson TA, Martin JR, Hanson EC, Fuller J, Heung M, et al Impact of ultrafiltration on kidney injury after cardiac surgery: the Michigan Experience. Ann Thorac Surg. 2015;100:1683-8.

23. Matata BM, Scawn N, Morgan M, Shirley S, Kemp I, Richards S, et al A single-center randomized trial of intraoperative zero-balanced ultrafiltration during cardiopulmonary bypass for patients with impaired kidney function undergoing cardiac surgery. J Cardiothorac Vasc Anesth. 2015;29:1236-47.

24. Despotis GJ, Joist JH, Hogue CW Jr, Alsoufiev A, Joiner-Maier D, Santoro SA, et al. More effective suppression of hemostatic system activation in patients undergoing cardiac surgery by heparin dosing based on heparin blood concentrations rather than ACT. Thromb Haemost. 1996;76:902-8.

25. Hori D, Everett AD, Lee JK, Ono M, Brown CH, Shah AS, et al. Rewarming rate during cardiopulmonary bypass is associated with release of glial fibrillary acidic protein. Ann Thorac Surg. 2015;100:1353-8.

26. Grigore AM, Grocott HP, Mathew JP, Phillips-Bute B, Stanley TO, Butler A et al. The rewarming rate and increased peak temperature alter neurocognitive outcome after cardiac surgery. Anesth Analg. 2002;94:4-10, table of contents.

27. Hori D, Hogue C, Adachi H, Max L, Price J, Sciortino C, et al. Perioperative optimal blood pressure as determined by ultrasound tagged near infrared spectroscopy and its association with postoperative acute kidney injury in cardiac surgery patients. Interact Cardiovasc Thorac Surg. 2016;22:445-51.

28. Leuven E, Sianesi B. PSMATCH2: Stata module to perform full Mahalanobis and propensity score matching, common support graphing, and covariate imbalance testing. Available at: http://EconPapers.repec.org/RePEc:boc:bocode: s432001. Accessed July 20, 2016.

29. Mangano CM, Diamondstone LS, Ramsay JG, Aggarwal A, Herskowitz A, Mangano DT. Renal dysfunction after myocardial revascularization: risk factors, adverse outcomes, and hospital resource utilization. The Multicenter Study of Perioperative Ischemia Research Group. Ann Intern Med. 1998;128: 194-203.

30. Grunenfelder J, Zund G, Schoeberlein A, Maly FE, Schurr U, Guntli S, et al. Modified ultrafiltration lowers adhesion molecule and cytokine levels after cardiopulmonary bypass without clinical relevance in adults. Eur J Cardiothorac Surg. 2000;17:77-83.

31. Gaynor JW. The effect of modified ultrafiltration on the postoperative course in patients with congenital heart disease. Semin Thorac Cardiovasc Surg Pediatr Card Surg Anпи. 2003;6:128-39.

32. Tassani P, Richter JA, Eising GP, Barankay A, Braun SL, Haehnel CH, et al. Influence of combined zero-balanced and modified ultrafiltration on the systemic inflammatory response during coronary artery bypass grafting. J Cardiothorac Vasc Anesth. 1999;13:285-91.

33. Luciani GB, Menon T, Vecchi B, Auriemma S, Mazzucco A. Modified ultrafiltration reduces morbidity after adult cardiac operations: a prospective, randomized clinical trial. Circulation. 2001;104:1253-9.

Key Words: acute kidney injury, cardiopulmonary bypass, CPB inflammatory response, goal-directed perfusion, kidney, postoperative care, renal failure 


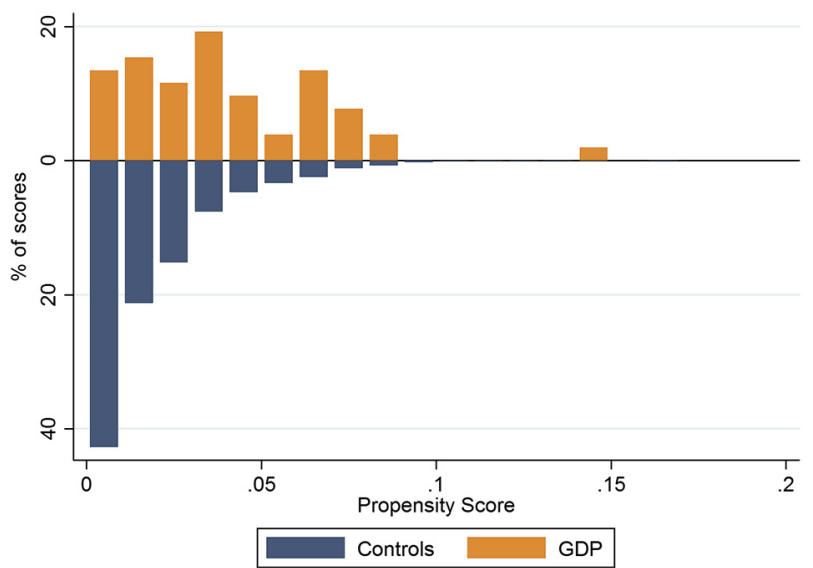

FIGURE E1. Mirror histogram showing distribution of propensity scores in GDP and control patients. GDP, Goal-directed perfusion.

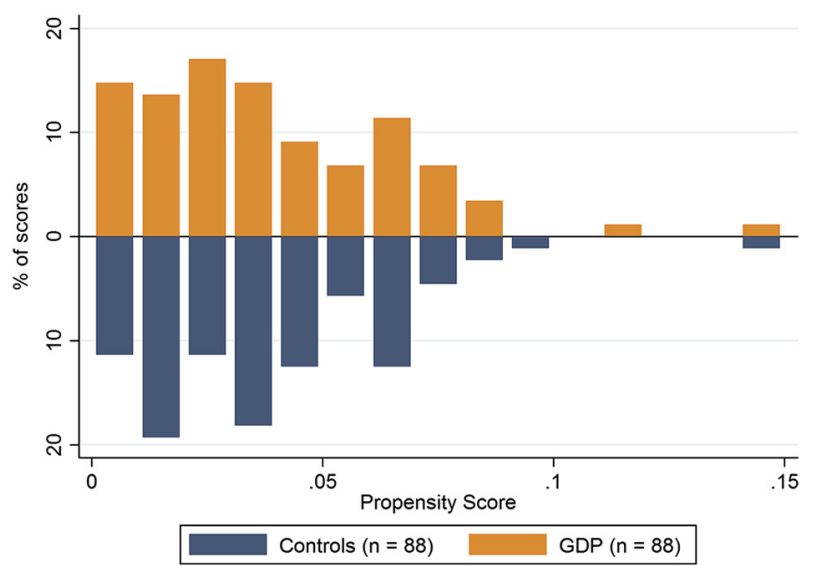

FIGURE E2. Mirror histogram showing distribution of propensity scores in GDP and control patients after matching. GDP, Goal-directed perfusion. 